\title{
PEMODELAN KARAKTERISTIK BAHAN BAKAR DIESEL MENGGUNAKAN MATLAB
}

\author{
Wahyu A. ${ }^{*}$, Hadi H. ${ }^{2}$, Handika D.K. ${ }^{3}$ \\ ${ }^{1,2}$ Jurusan Teknik Mesin, Politeknik Negeri Balikpapan \\ ${ }^{3}$ Mahasiswa DIII Jurusan Teknik Mesin, Politeknik Negeri Balikpapan \\ *email : wahyu.anhar@poltekba.ac.id
}

\begin{abstract}
This study aimed to investigate the characteristic model of dynamic viscosity, kinematic viscosity, and density on diesel fuel. The characteristic of diesel fuel modelled using computer aided MATLAB. The fuel derived model object consist of diesel fuel, and diesel fuel blend with etanol nor metanol. Furthermore, the characteristic model of diesel fuel using MATLAB compared with result of characteristic by experiment. The results showed that the characteristic model of diesel fuel, can be done by MATLAB.
\end{abstract}

Keywords : MATLAB, viscosity, density

\begin{abstract}
Abstrak
Penelitian ini dilakukan dengan tujuan untuk dapat memodelkan karakteristik bahan bakar diesel meliputi viskositas dinamik, viskositas kinematik, dan densitas. Karakteristik bahan bakar diesel dimodelkan dengan bantuan program komputer MATLAB. Bahan bakar yang dijadikan obyek pemodelan adalah bahan bakar solar, dan solar dengan campuran etanol maupun metonol. Pemodelan karakteristik bahan bakar diesel menggunakan MATLAB dibandingkan dengan hasil karakteristik secara eksperimen. Hasil penelitian menunjukkan bahwa dapat dilakukan pemodelan terhadap karakteristik bahan bakar diesel menggunakan MATLAB.
\end{abstract}

Kata kunci : MATLAB, viskositas, densitas

\section{Pendahuluan}

MATLAB atau Matrix Laboratory adalah suatu program yang digunakan untuk menganalisa dan mengkomputasi data numerik. MATLAB juga digunakan sebagai bahasa pemprograman matematika lanjutan yang dibentuk dengan dasar pemikiran yang menggunakan sifat dan bentuk matriks. MATLAB memfokuskan terhadap komputasi teknik, visualisasi, dan pemprograman seperti komputasi matematika, analisis data, pengembangan algoritma, simulasi dan pemodelan, dan grafik-grafik perhitungan.

MATLAB dapat mensimulasikan perintah-perintah yang dibuat berdasarkan rumus perhitungan. Output MATLAB dapat berbentuk grafik dengan menggunakan rumus plot, dan juga dapat berbentuk gambar 2 dimensi dengan menggunakan rumus surf.

Shivanand dkk [1] melakukan pemodelan/simulasi menggunakan program MATLAB untuk mengkarakterisasi gas buang engine diesel. MATLAB dapat memodelkan evaluasi kinerja diesel engine yang menggunakan bahan bakar campuran (bahan bakar modifikasi) secara akurat.

$$
\text { Jiang [2] memodelkan }
$$
kemampuan anti-aliasing filter terhadap suatu gelombang frekuensi menggunakan bantuan MATLAB. Hasil pemodelan MATLAB dikoreksi menggunakan fifthorder Butterworth. Hasil script MATLAB telah dapat memodelkan parameterparameter yang diperlukan dalam perancangan anti-aliasing filter.

An dkk [3] meneliti tentang pemodelan logix gear menggunakan 
MATLAB. Hasil penelitian tersebut telah dapat memodelkan profil gigi (tooth profile) logix gear, dan kurva koordinat center lingkaran logix rack dan logix gear. Hasil pemodelan tersebut akan membantu dalam proses model matematika, dan manufaktur.

Agarwal dkk [4] memodelkan proses produksi bahan bakar biodiesel khususnya proses penyulingan. Pemodelan menggunakan MATLAB, dan hasil pemodelan divalidasi menggunakan CHEMCAD. Hasil pemodelan memudahkan penentuan komposisi dan yield dalam kolom reactive distillation pada produksi biodiesel.

Shuai [5] memodelkan overhead pembungkus (shielded) kabel elektronik. Jenis pembungkus kabel yang dimodelkan adalah pembungkus kabel untuk jenis coaxial cable, dan two-core cable. Menggunakan linear boundary element method (LBEM) dalam program MATLAB, telah berhasil memodelkan overhead lapisan pembungkus kabel.

Liu dan Zhi Liu [6] melakukan penelitian untuk memodelkan getaran yang terjadi pada alat mould hydraulic. Proses pemodelan menggunakan perangkat Simulink dalam MATLAB. Hasil pemodelan sangat membantu dalam merancang mould hydraulic agar stabil, dan secara efektif meningkatkan keakuratan sistem.

Zhenjun dkk [7] melakukan pemodelan tentang kinerja permesinan menggunakan MATLAB. Pemodelan difokuskan terhadap abrasi dan jarak kontak mekanisme cam. Mekanisme cam yang dimodelkan adalah tipe offset translation roller disc-shaped, dan tipe flat-bottomed translation follower. Dengan bantuan MATLAB diketahui mekanisme kontak permukaan, bagaimana abrasi dan jarak kontak antar tiap sisi, dan bagaimana abrasi dan jarak kontak mempengaruhi keakuratan kinematik mekanisme cam. Berdasarkan permodelan dapat ditingkatkan ketahanan abrasi, keakuratan kinematik, dan ketahanan mekanisme cam.

\section{Metode Penelitian}

Pemodelan menggunakan bantuan program komputer MATLAB. Obyek penelitian adalah karakterisasi densitas, viskositas dinamik, dan viskositas kinematik, bahan bakar diesel. Penelitian ini membandingkan hasil eksperimen terhadap hasil pemodelan menggunakan MATLAB. Bahan yang digunakan adalah solar dari SPBU Pertamina, etanol dan metanol murni (kadar $\geq 99,9 \%$ ) merek Emsure produksi Jerman. Variasi campuran bahan bakar yang akan dimodelkan adalah solar (Solar), etanol 5\%-solar 95\% (S5E), etanol 10\%-solar 90\% (S10E), metanol 5\%-solar 95\% (S5M), dan metanol 10\%-solar $90 \%$ (S10M).

\section{Pemodelan Komputer}

Persamaan (1-6) digunakan sebagai input data/data awal.

$$
\begin{gathered}
d \_s o l=839 \ldots . \\
d \_e t=792 \ldots \ldots \\
d \_ \text {met }=793 \ldots \ldots \\
v \_ \text {dinsol }=3,4 \ldots \\
v \_ \text {dinet }=0,79 \ldots \\
v \_ \text {dinmet }=0,45 .
\end{gathered}
$$

dimana:

d_sol : densitas solar $\left(\mathrm{kg} / \mathrm{m}^{3}\right)$

d_et : densitas etanol $\left(\mathrm{kg} / \mathrm{m}^{3}\right)$

d_met : densitas metanol $\left(\mathrm{kg} / \mathrm{m}^{3}\right)$

v_dinsol : viskositas dinamik solar (mPa.s)

v_dinet : viskositas dinamik etanol (mPa.s)

v_dinmet : viskositas dinamik metanol (mPa.s)

Untuk dapat menjalankan pemodelan campuran bahan bakar maka dibuat script MATLAB seperti pada Persamaan (7-12).

$d v \_c a m p u r a n \_t o t(i+1,1)=d \_s o l *(100$ i) $/ 100+d \_e t * i / 100$;

$d v \_c a m p u r a n \_t o t(i+1,2)=\left(v d i n \_s o l a r *(100\right.$ -

i)/100+vdin_et*1/100); 
$d v \_c a m p u r a n \_t o t(i+1,3)=\left(v d i n \_s o l / d \_s o l *(100\right.$ -

i)/100+vdin_et/d_et*i/100)*1000;

$d v \_c a m p u r a n \_t o t(i+1,4)=d \_s o l *(100$

i) $/ 100+d \_m e t * i / 100$;

$d v \_c a m p u r a n \_t o t(i+1,5)=\left(v d i n \_s o l *(100-\right.$

i)/100+vdin_met $* i / 100)$;

$d v \_c a m p u r a n \_t o t(i+1,6)=\left(v d i n \_s o l / d \_s o l *(100-\right.$

i) $\left./ 100+v d i n \_m e t / d \_m e t * i / 100\right) * 1000$;

\section{Hasil Penelitian}

Grafik densitas hasil pemodelan dan eksperimen untuk seluruh variasi pencampuran bahan bakar ditunjukkan dalam Gambar 1.

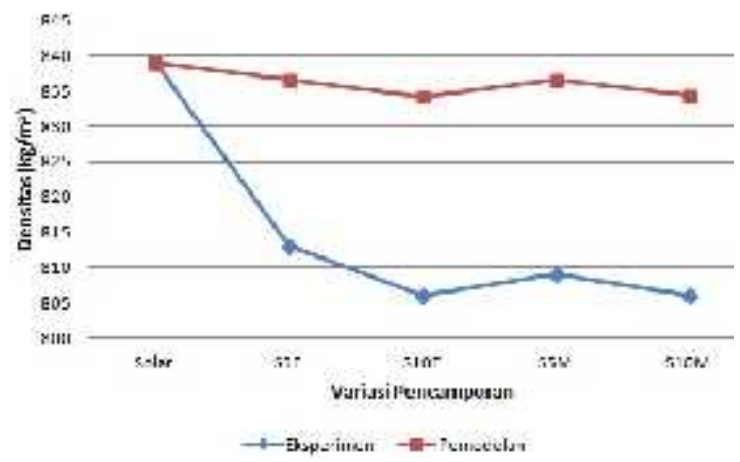

Gambar 1. Grafik densitas hasil pemodelan dan eksperimen

Gambar 2 menunjukkan grafik viskositas dinamik hasil pemodelan dan eksperimen untuk seluruh variasi bahan bakar.

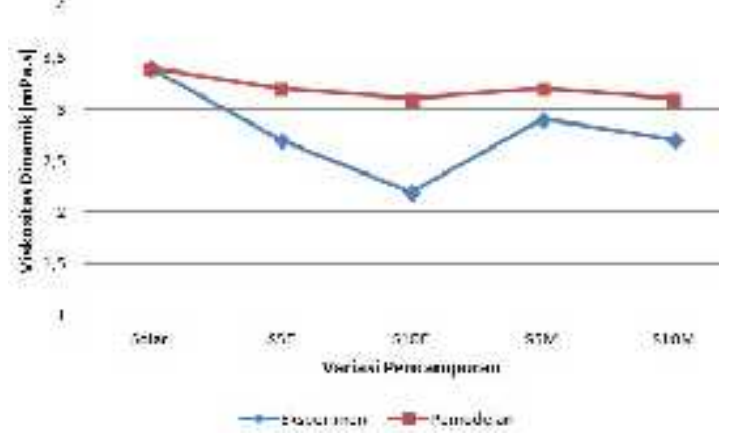

Gambar 2. Grafik viskositas dinamik hasil pemodelan dan eksperimen

Gambar 3 menunjukkan grafik viskositas kinematik hasil pemodelan dan eksperimen untuk seluruh variasi bahan bakar.

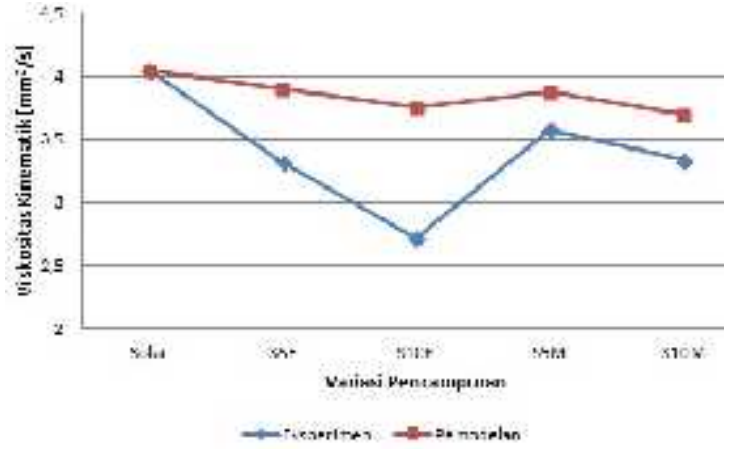

Gambar 3. Grafik viskositas kinematik hasil pemodelan dan eksperimen

Hasil pemodelan menggunakan MATLAB untuk densitas, viskositas dinamik, dan viskositas kinematik menghasilkan data rata-rata lebih tinggi daripada hasil eksperimen. Hal ini disebabkan karena dalam proses eksperimen terdapat faktor eror. Sesuai dengan nilai simpangan baku yang ditunjukkan dalam Tabel 1, bahwa hasil eksperimen memiliki nilai simpangan baku yang lebih besar daripada hasil pemodelan.

Tabel 1. Simpangan baku

\begin{tabular}{lcc}
\hline \multirow{2}{*}{ Karakteristik } & \multicolumn{2}{c}{ Simpangan baku } \\
\cline { 2 - 3 } & Eksperimen & Pemodelan \\
\hline Densitas & 12,47 & 1,74 \\
Viskositas & 0,31 & 0,1 \\
dinamik & & \\
$\begin{array}{l}\text { Viskositas } \\
\text { kinematik }\end{array}$ & 0,35 & 0,12 \\
\hline
\end{tabular}

Pemodelan menunjukkan penurunan sifat densitas, viskositas dinamik, dan viskositas kinematik bahan bakar dengan adanya penambahan etanol maupun metanol. Pola grafik pemodelan sama dengan pola grafik hasil eksperimen.

\section{Kesimpulan}

Karakteristik variasi campuran bahan bakar meliputi densitas, viskositas dinamik, dan viskositas kinematik dapat dimodelkan menggunakan bantuan program komputer MATLAB.

Terdapat selisih antara hasil pemodelan dengan hasil eksperimen, tetapi pola keduanya adalah sama yaitu terjadi 
penurunan karakteristik dengan adanya penambahan etanol maupun metanol.

\section{Saran}

Pemodelan dapat dilakukan terhadap karakteristik bahan bakar lainnya, seperti cetane number, sisa karbon, higher heating value (HHV), kandungan sulfur, kandungan asam dan lain sebagainya.

\section{Daftar Pustaka}

[1] Shivanand, H.K., Gowda, P.B., Rajanna, S., Raju, H.G.H., 2009, Computer Simulation Study Of Exhaust Gas Characters In A Diesel Engine Operating With Blended Fuels, International Journal of Recent Trends in Engineering, Volume 1: 156158.

[2] Jiang, X., 2011, Research Of Computer Aided Design For AntiAliasing Filter Based On MATLAB, Applied Mechanics and Materials, Volume 88-89: 145-149.

[3] An, A., Pang, M., Zhang, L., Nie, Y., 2011, The StudyingOf Logix Gear Construction Principle And Parameter Simulation Using MATLAB, Applied Mechanics and Materials, Volume 80-81: 1118-1122.
[4] Agarwal, M., Singh, K., Chaurasia, S.P., 2012, Simulation And Sensitivity Analysis For Biodiesel Production In A Reactive Distillation Column, Polish Journal of Chemical Technology, Volume 14: 59-65.

[5] Shuai, C.J., 2013, Analysis On Overhead Shielded Coupling Effectiveness Of Ring Seam By MATLAB, Journal of Computers, Volume 8: 1979-1986.

[6] Liu, X., Liu, Z., 2013, Simulation Of Mould Hydraulic Vibration System Based On MATLAB, Applied Mechanics and Materials, Volume 246-247: 1299-1303.

[7] Zhenjun, H.E., Peng, X.U., Jianrong, L.U., 2013, Abrasion, Clearance And MATLAB -Aided Optimized Profile Design Of Cam Mechanism, Applied Mechanics and Materials, Volume 416417: 1120-1125. 